\title{
Fair Value between Perception and Reality
}

\author{
Ionica Oncioiu* \\ * Tomis University of Constanta, 5A Brizei Street, Bl. FB7A, ap. 1, Constanta, Romania \\ Tel: 40-744-322-911Ｅ-mail: nelly_oncioiu@yahoo.com
}

Received: January 28, 2012 Accepted: February 26, 2012 Published: April 4, 2012

doi:10.5296/rae.v4i2.1315 URL: http://dx.doi.org/10.5296/rae.v4i2.1315

\begin{abstract}
Many of the authors are presenting the advantages of fair value, but there are voices contesting this concept, because of its volatility and the tendency to subjectivism, to the manipulation of used models for evaluation.

Among the advantages of fair value the following must be mentioned: utility, relevance, transparency and superior accuracy of the results and cash-flow of the company, more clearance to financial statements, total accounting of the comparable value and greater liability to the manager.

However, those who criticize fair value accounting do not seem to provide any credible alternatives. Do we go back to historical cost accounting, wherein the financial assets are stated at outdated values and hence are not relevant or reliable? In the current crisis, one of the questions that were raised is: Should assets be marked down to their current throw away prices, as companies may not want to sell them at those values?

This paper analyses the answer to this question, and also various controversial issues of the concept of fair value as it is presented in the current project of the IASB and FASB.
\end{abstract}

Keywords: fair value; standards; accounting; assets; liabilities 


\section{Introduction}

Fair value is a relatively new concept. It did not feature in the academic debate on current values in accounting that raged (not too strong a term) in the 1960s. In those days, the current values were debated as alternatives to historical cost, and to one another, were replacement cost (Günter 1966), net realizable value (Chambers 1967) and deprival value (Baxter 1967). The term 'fair value' seems to have been used first by accounting standards setters in the United States and has subsequently appeared in UK standards, in international standards and in the Directives of the European Commission, in addition to some more recent standards in the US. The use of the term by standards setters has been to describe, rather loosely, a market-based current value, as opposed to traditional historical cost. The precise application of fair value has varied from standard to standard, and the United States Financial Accounting Standards Board (FASB) has recently developed a standard which prescribes a uniform method of calculating fair value, to apply within all standards that currently use the term. An exposure draft was issued in 2004 and the final standard was published in September 2006. The International Accounting Standards Board (IASB) is committed, as part of its international convergence program, to issuing a discussion paper (the first stage of its due process for developing a standard) based on the new FASB standard.

In this context, the national and international intercessions have as target the realization of a convergence between national and international norms for a unique value (faire value). The application of this concept imposes the outlining of its utility, the knowledge of attainting techniques, assures much better than the historical cost the qualitative accountancy information and gives a plus to the user's certainty, because this one will be able to avoid the negative aspects, referring to the interest-evaluations and reliability of a patrimonial entity.

With the FASB having decided, in Statement of Financial Accounting Standards 157 Fair Value Measurement, that fair value is an exit price notion; the IASB is left to decide whether or not it agrees. Preliminary indications are that while the IASB may largely agree with the FASB's articulation of exit price, it may also see the need to articulate an entry price notion, because of the perceived use of that notion under the banner of fair value in some IASB standards. More specifically, some may make the case for the use of entry price on initial recognition of an asset or liability with a switch to exit price for subsequent measurement.

The fair value option is a step in the direction of making US GAAP more harmonized with international GAAP, but it is a very small step. The main point in this module is that fair value adjustment of all financial and non-financial items on the balance sheet will not necessarily bring the balance sheet significantly closer to the fair value of the firm as a whole. The problem is that the value of the firm is most likely highly impacted by unregistered items that are not on the balance sheet and cannot be adjusted for fair value. Debate should therefore centre on the measurement attribute to be used in assessing an asset's recoverability; fair value, or the higher value in use and the fair value which costs less to sell.

According with IFRS 13 changes in fair values reflect the effects of changes in market conditions when they occur. Therefore, they reflect the effects of management decisions to buy, sell, incur, extinguish or hold financial assets or financial liabilities on a timely basis. 


\section{Literature review}

Fair value is usually defined as a current market price. The definition in current international financial reporting standards (IFRS) is: „The amount for which an asset could be exchanged, a liability settled, or an equity instrument granted could be exchanged, between knowledgeable, willing parties in an arm's length transaction" (IASB 2006, 2304).

The FASB fair value measurement standard defines fair value as follows:"Fair value is the price that would be received to sell an asset or paid to transfer a liability in an orderly transaction between market participants at the measurement date" (FASB 2006).

The new definition resolves two of the alternatives within fair value as follows:

The reference to price rather then amount makes it clear that transaction costs are not included in fair value. If they are included in the measurement, the correct description would, in the case of assets, be 'fair value, less cost to sell'.

The reference to received to sell an asset and paid to transfer a liability clarify the choice of market, by specifying the exit market (disposal) rather then the entry market (acquisition).

There are two distinct dimensions to the consideration of alternatives to fair value. The first is to examine alternative current values, and the second is to consider historical costs. Discussions of fair value often fall into the trap of debating the relative merits of fair value and historical cost while ignoring the existence of alternative current values. Thus fair value can, wrongly, be regarded as the only alternative to historical cost. In order to avoid giving this false impression, the current discussion will focus first on alternative measures of current value.

Like fair value, the other current value measures have a number of alternative definitions and their classification into generic groups is far from simple. Here we shall adopt the classification used by the Discussion Paper on measurement bases, published recently by the IASB (IASB 2005). APB Opinion No. 16 (1970) on business combinations in an early example. The term 'fair value' subsequently became widely used to describe the measurement basis used in the revaluation exercise required by acquisition accounting for initial recognition of an acquired entity. This includes an entry value, current cost (subdivided into reproduction cost and replacement cost), two exit values (net realizable value and value in use) and one method that combines both entry and exit values (deprival value). For the sake of simplicity, the subsequent discussion is conducted in terms of measuring assets, although most but not all of it is equally relevant to liabilities. For example, due to the financial nature of liabilities, the distinction between reproduction cost and replacement cost is not generally relevant to them. A useful analysis of the recognition and measurement of liabilities is Leonard in 2002.

It is not surprising that there appears to be some consistency between the recent IASB statements discussed above and recent FASB comments. On 23 June 2004, FASB issued an Exposure Draft of a proposed Statement, 'Fair Value Measurements'. This proposes a definition of fair value as 'the price at which an asset or liability could be exchanged in a 
current transaction between knowledgeable, unrelated willing parties', which definition seems at pains to preserve semantic differences between FASB and IASB, rather than to seek convergence. FASB proposes a hierarchy of the inputs which should be used to estimate fair value (note that this hierarchy is concerned with measurement estimations, not with definition).

At the joint meeting of the IASB and the FASB in October 2005, the boards established explicit long-term objectives for improving financial reporting for financial instruments, to help the boards evaluate and prioritize future projects on financial instruments. In addition, the boards agreed to work towards those long-term objectives while retaining the ability to work either jointly or separately (if necessary) on shorter term objectives that are consistent with the long-term objectives.

An interesting slant on all this is given by the Discussion Paper Measurement Bases for Financial Accounting-Measurement on Initial Recognition (IASB, 2005). This document was written by the staff of the Canadian Accounting Standards Board and published for discussion by IASB, and several other bodies. This proposes a four-level measurement hierarchy for assets and liabilities on initial recognition, as follows:

- Level 1 Observable market prices; any adjustments are consistent with those that market participants may be expected to make.

- Level 2 Accepted valuation models or techniques; all significant inputs are consistent with those that market participants may be expected to use.

- Level 3 Current cost (i.e. reproduction cost and replacement cost); with the possibility of substituting historical cost, provided a reliable estimate can be made and the amount may be expected to be recoverable.

- Level 4 Models and techniques that use entity-specific inputs only; when unavoidable and when not demonstrably inconsistent with those that market participants can be expected to use.

In 2006, FASB issued a new standard, FAS No. 157, Fair Value Measurements, which provided a single, consistent definition of fair value, established a common framework for developing fair value estimates, and required expanded disclosures about those estimates. FASB issued FAS 157 to address the complexities caused by differing definitions of fair value. Stated differently, FAS 157 itself does not prescribe any particular accounting treatment or require fair value accounting but does specify how fair value is to be determined when fair value is required by another standard.

FAS 157 establishes a hierarchy of valuation techniques that varies based on the availability of observable market information:

- Level 1 inputs are "observable market data" - such as the quoted price for an identical stock or bond in an active market;

- Level 2 inputs are "other observable market data" - such as quoted prices for similar 


\section{$\triangle$ Macrothink}

assets or liabilities in active markets; quoted prices for identical or similar assets or liabilities in inactive markets; interest rate, yield curve and similar data that are observable at commonly quoted intervals; and other data that may be corroborated by market data (mark-to-market measurements); and

- Level 3 inputs are "unobservable firm supplied estimates," including the reporting entity's own analysis of the underlying economic data that market participants would factor into the pricing of the asset or liability (mark-to-model valuations).

Convergence regarding faire value does not mean however the failure of accounting harmonization, but an obvious intercession aimed towards using an appropriate communication in a globalizing context, with the goal of having a common reference, International Financial Reporting Statements, while the short term goal of convergence is to eliminate the individual differences between US GAAP and the current IAS IFRS. Within this short term project, FASB analyzes various issues and either suggests alterations in the American norms, in order to eliminate the differences found, or it communicates to IASB the reason for which it decided not to alter the provisions of US GAAP, while at the same time IASB is carrying on a process of revising IFRS, taking, as the case may be, the same measures as FASB.

On 12 May 2011 the IASB and the Financial Accounting Standards Board (FASB) issued new guidance on fair value measurement and disclosure requirements for International Financial Reporting Standards (IFRSs) and US generally accepted accounting principles (GAAP). The concept in IFRS 13 is that there are many types of factors which are taken into account in fair value. We can estimate if they are (1) a characteristic of the asset or liability in question (rather than a characteristic of the entity that holds the item); and (2) they would influence market participants' pricing decisions. Even though IFRS 13 became a convergence guide regarding fair value, there are also differences between US GAAP and IFRS which refer to:

1) The recognition of day one gains and looses when fair value is determined using unobservable inputs;

2) The measurements as a certain alternative have a practical expedient in an investment company without a readily determinable fair value.

To sum up, IFRS 13 clarifies that fair value is a current price at the measurement date and explicitness reference to 'market participants', emphasizing that fair value is a market-based concept and assuming an orderly sale or transfer. There are also specialists who criticize the limited use of fair values in IFRS.

\section{The Fair value against the Historical cost}

Historical cost is the method of measurement traditionally used by accountants. It measures an asset at the cost of acquiring it. This provides a reliable basis for measurement, but an obvious disadvantage is that, as price changes subsequent to acquisition, the relevance of historical cost declines if the objective of measurement is to reflect the current economic 
benefit represented by the asset. Moreover, it is possible that, in some cases, the transaction did not take place at market price (as in the case of bargain purchase) so that the transaction price did not represent the current economic benefit conferred by the asset, even at the moment of purchase. This comparison holds between historical cost and each of the current value alternatives described above. Each of the current values measures a current rather than an historical attribute of the asset and looks to the market rather than the specific transaction for evidence, but this leads, in each case, to a degree of estimation, because the current measures are not based on actual transactions but upon transactions that might take place in markets that are far from perfect and, in the extreme, may not even exist. Hence, current values include gains or losses in value that are unrealized, whereas historical cost does not amend the measurement arising from the acquisition transaction until the gain or loss are realized in a disposal transaction.

These benefits of historical cost are obtained by sacrificing relevance to the current economic opportunities represented by the asset. From that perspective, historical cost loses its relevance as time passes and prices and opportunities change. Moreover, historical cost will measure otherwise identical assets of the same entity at different amounts, depending on the specific acquisition cost prevailing at the time of acquisition. Thus, it does not provide either a timely or a comparable basis for measuring the economic benefits conferred by the ownership of asset.

There are clearly several plausible alternatives to fair value. In choosing between them, it is necessary to have criteria with which to weigh their relative costs and benefits. The conceptual framework of various accounting standard settlers attempt to provide such criteria, although no standard setter has yet taken the courageous step of choosing a single valuation basis which is considered to be generally superior to the others. Thus, the extant standards are based upon mixed measurement systems. Current values and historical costs are used in different standards and sometimes as alternatives within the same standard. The selection of alternative current values also varies: sometimes it is described as fair value and other time is not (e.g. the use of 'fair value less cost to sell' in IAS 36). Even when fair value is the prescribed measure, as in several of the current IASB and FASB standards, the precise application of the term is not the same across different standards: removing such inconsistencies is the main objective of the current FASB and IASB project in fair value measurement.

The fundamental measurement issue is not application guidance and the choice of evidence to support measurement, but rather it is to determine the guiding objective of the measurement process. The primary objective of account, and therefore of measurement in accounts, is, according to the conceptual framework of the IASB and the FASB, relevance to the need of users. Those needs are assumed to arise from the economic decisions that users have to make. These decisions are assumed to be primarily those made by an investor, and they therefore relate primarily to the prediction of future cash flows. However, prediction does not imply merely forecasting, and the concerns of stewardship are also assumed to be included in the objective. Stewardship implies accountability by management to investors. The feedback that this provides is relevant to future cash flows because it will affect the future conduct of 
management and confidence which investors will place in the entity's prospects.

In practice, therefore, cost/benefit considerations seem to rule out an unconstrained multiple column approach, and the need for comparability suggests that the single measurement that is given prominence in the accounts should be chosen by reference to consistent guidance, so that like transactions and events are recorded in a similar manner. This requirement does not rule out measurement methods such as deprival value, which may use a different measurement method in different circumstances, because such a method will always treat like circumstances is a similar manner. Equally, it does not rule out systematic valuation of different types of asset on a different basis (e.g. current assets at selling price and fixed assets at cost); such an approach might be chosen on cost/benefit grounds (e.g. if fixed assets are expensive to value and the resulting valuation are unreliable). However, when the cost measure used is the historical cost, it could be argued that such measures cannot be compared in an economically meaningful way because the measure is dependent on the time of acquisition, which will differ across different assets.

Many academic writers have advocated that a single measurement method should be applied to all assets. This would have the obvious benefit of enabling different types of asset to be compared without having to allow the changes in valuation method and would also remove possible errors or bias arising from different classification methods being used by different entities or at different times. However, it seems likely that, in practice, cost/benefit considerations may justify the use of different measurement methods for different categories of asset (e.g. when market evidence is unavailable or expensive). In the latter case, it may still be helpful to users to have a common valuation objective, imposing consistency of purpose, even if the techniques used to achieve it may vary according to asset type. Moreover, it may be preferable to choose techniques by reference to specific circumstances rather than asset type: thus, it would be the actual absence of market information, rather then asset type that would justify the use of an alternative technique, so that the measurement objective would always be followed as closely as was permitted by the available evidence. This is the approach adopted by the fair value hierarchy discussed above.

The positive result of the theoretical debates of the 1960s was to demonstrate the potential usefulness of different current valuation bases, such as replacement cost, net realizable value and deprival value.

Fair value accounting - also referred to as "mark-to-market" accounting - has played an important role in U.S. generally accepted accounting principles (GAAP) for more than 50 years.

Beginning in 1979, SFAS 33 required large corporations to provide a supplementary schedule of condensed balance sheets and income statements comparing annual outcomes under three valuation bases: Unadjusted historical cost, Price-level adjusted (PLA) historical cost, and Current cost entry value (adjusted for depreciation and amortization). Companies complained heavily that user did not obtain value that justified the cost of implementing SFAS 33 . Analysts complained that the FASB allowed such crude estimates that the SFAS 33 schedules were virtually useless, especially the current cost estimates. The FASB rescinded SFAS 33 
when it issued SFAS 89 in 1986.

In 1993, FASB expanded the fair value recognition requirements by issuing a standard that required debt and equity securities that were held for trading or held for sale to be carried at fair value in the balance sheet and required changes in fair value to be recognized in the income statement or in a category of equity referred to as other comprehensive income. This was augmented in 1998, when FASB standards were adopted that required derivatives to be measured at fair value.

The new concept regarding harmonization or the convergence is concerning all together the professional organizations and the users of this concept of the faire value. The International Accounting Standards Board (IASB) and the Financial Accounting Standards Board (FASB) make mention that fair value is used extensively or excessively. Although, the conceptual frameworks were published some time ago, we have witnessed a meteoric rise in the use of fair value as a measurement basis in financial reporting. The great challenge in recent decades is related to the identification of methods and indicators able to measure the effects that fair value produces in the new economy. Thus, the most recent studies have focused on developing tools to facilitate a better understanding and representation of fair value, meaning of this concept recognized and presented in a form without substance and in a substance without form.

\section{Conclusions}

To conclude, there are a number of plausible alternatives to fair value and that the choice will depend upon the specific circumstances of the entity and the needs of the user of accounts. In an uncertain world with imperfect and incomplete markets, no particular measurement objective should be regarded as having a monopoly, and different measurements should be regarded as complementing one another.

Fair value is here to stay. It is already deeply embedded in IASB and FASB literature and there are growing calls from the user community to increase its use in financial reporting. Conceptual support for fair value is demonstrable and will be further underpinned in the revised conceptual framework. Users, auditors and regulators will become more comfortable with the use of fair value as time passes.

Moving from theory to practice, the question perhaps becomes: What are the informational advantages and disadvantages of the practicable proxies to fair value, value, both when applied consistently, and when applied pragmatically on an item-by item basis? This takes us back to the academically traditional debates on the pros and cons of the various theories of income measurement and asset valuation. Many academics have strongly held view on these issues. But since the fair value notion seems not to alter these debates, we leave our views until another occasion.

The credibility regards a reasonable evaluation, the using of market information in all possible situations for evaluating and justifying the subjective arguments. Starting from these concepts, the users of the accountancy information had demanded the elaborating of a model for a general appliance of the fair value. 
In essence, therefore, this concept in context of new economy gives a significant push towards current values in general and towards fair value in particular, but also strongly insists that fair value, as such must be genuinely based on market expectations, i.e. again, not entity- specific.

We consider that fair value is an attempt at current economic values, and current value in an active market is a proxy for it (in which case ignoring transaction costs is correct and necessary, because current economic value does not imply a current market transaction). But whether or not IASB sees it this way is not proven.

In conclusion is strongly supportive of current values and regards fair value as a valid contender for an appropriate current value, but, like EFRAG, is not at all convinced by the apparent determination to avoid entity-specific measurements.

Convergence especially regarding fair value is not an easy thing! Even the president of FASB declared that the greatest challenge of the convergence process was to persuade the national business communities about the necessity for an international accounting language. Even if Securities Exchange Commission (SEC) and the multinational companies in the USA are privileged by this convergence, the small companies and the family level businesses are less happy. Perhaps people don't like change in general, preferring rather to keep their status quo.

IFRS 13, which is effective from 1 January 2013, defines fair value, sets out in a single IFRS a framework for measuring fair value and requires disclosures about fair value measurements. IFRS 13 does not determine when an asset, a liability or an entity's own equity instrument is measured at fair value. Rather, the measurement and disclosure requirements of IFRS 13 apply when another IFRS requires or permits the item to be measured at fair value (with limited exceptions).

We can conclude that IFRS 13 Fair Value Measurement will improve consistency and reduce complexity by providing, for the first time, a precise definition of fair value and a single source of fair value measurement and disclosure requirements for use across IFRSs. On the other side, this standard reflects the FASB's consideration of the different characteristics of public and non-public entities and the needs of users of their financial statements.

\section{References}

Alexander, D. (2006). Globalization of accounting standards: a UK perspective, in Jayne M. Godfrey and Keryn Chalmers. 9781845428525

Clark, G., Hebb T., \& Wojcik D. (2006). Institutional investors and the language of finance: the global metrics of market performance, in Jayne M. Godfrey and Keryn Chalmers. http://dx.doi.org/10.2139/ssrn.675779

Ernst \& Young. (2011). How far is Fair Value? London: Ernst \& Young.

Evraert, S., \& Jean Francois des Robert. (2006). French accounting revolution: Implementing IFRS in French companies, in Jayne M. Godfrey and Keryn Chalmers. 
FASB. (2011). Fair Value Measurements, Statement of Financial Accounting Standards No. 157.

IASB, (2011). International Financial Reporting Standards. International Accounting Standards Foundation, London.

Leonard, A. (2002). Liabilities and How to Account for Them: An Exploratory Essay, Accounting Standards Board, London. http://dx.doi.org/10.1108/09657960310698173

Marr, B. (2008). Intangible Asset Measurement. Retrieved from: www.mia.org.my/at/at/200811 /06.pdf

McConnell, P. (2010). Response to "Fair Value Accounting, Financial Economics, and the Transformation of Reliability”. Accounting and Business, Vol. 40, No. 3, page 211-213. Retrieved from: http://scholar.google.com/scholar?hl=en\&btnG=Search\&q=intitle:Response+to+"Fair+V alue+Accounting,+Financial+ +Economics,+and+the+Transformation+of+Reliability

PricewaterhouseCoopers, (2010). AIFRS and IFRS - Similar but Not the Same. PricewaterhouseCoopers, Australia. Research

Report and Recommendations Pursuant to Section 133 of the Emergency Economic Stabilization Act of 2008: Study on Mark to Market Accounting, Page 14, United States Securities and Exchange Commission, December 2008.

Stevenson K. (2006). The IASB: Some personal reflections, in Jayne M. Godfrey and Keryn Chalmers.

Van, T., \& Whittington, G. (2006). Deprival Value and Fair Value: A Reinterpretation and Reconciliation, Accounting and Business Research. London. Retrieved from: http://hdl.handle.net/10063/201

http://thornton.no/files/gti_ifrs_news_special_edition_october_2011.pdf

http://www.iasplus.com/standard/ifrs13.htm

\section{Copyright Disclaimer}

Copyright reserved by the author(s).

This article is an open-access article distributed under the terms and conditions of the Creative Commons Attribution license (http://creativecommons.org/licenses/by/3.0/). 